knowledge of the birds' nesting habits and migration routes, and the strange inability of modern governments to co-ordinate the work of their various departments, made the attempt to save them particularly complicated. The US government, having established a refuge for the cranes on the coast of Texas allowed the air force to set up a bombing range on a nearby island and the Army Engineering Corps to construct a waterway on the edge of the refuge, draining acres of marsh in the process and giving easy access to the birds. The state government of Texas is apparently unsympathetic, and the bird is faced with a possible total loss of habitat through the building of a great irrigation canal and by the destruction of marine life through oyster dredging.

Attempts to breed the birds in captivity are not without success, but the author seems to show that if the wild birds disappear, it will be a long time before it is possible to return the captives to the wild with any expectation that man will allow them to exist. She herself appears to be more optimistic, and points out that to many people the cranes have become a symbol of the conservationist faith. But anyone who wishes to understand the pressures which impede attempts to save endangered species could not do better than read this book.

DIANA SPEARMAN

\title{
Wild Fox by Roger Burrows. David \& Charles, $42 s$. Otters, by C. J. Harris. Weidenfeld \& Nicolson, 5 guineas.
}

It is refreshing to read a book on a wild mammal based on personal observations. Not intended as a monograph, Wild Fox is an account of a serious personal investigation into the lives of foxes in a farming area in Gloucestershire. Because of this more limited approach it has the merits of intimate personal observations and deductions, but also the disadvantages arising from only slight use of the findings of others.

Considering the limitations imposed by only three years of observations Roger Burrows has written a most useful book. Three years may seem a long time, but with an animal as difficult to observe as the fox it was hardly adequate to get enough data to prove or disprove some of his most interesting deductions. But it will stimulate others to follow in his footsteps, and this in itself is more than justification. Having described his technique for watching foxes and deducing their main activities from their signs, he discusses their senses, diet, reproduction, general behaviour and ecology. Not everybody will agree with all his findings, but this is no bad thing if it makes us re-appraise some of the 'facts' we had taken for granted.

In this first comprehensive account of the otters of the world the author has done zoologists a great service by collating the known facts. The book is the result of a remarkably thorough perusal of the extensive literature in twelve languages, and no serious student of the group can do without it. Although primarily an admirably arranged book of reference, there is much that is anecdotal, delightful and of great interest to the naturalist. The chapter on the natural history of the otter summarises what is known about mating behaviour, breeding habits, growth rate, and diet, and incidentally, by its relative shortness, emphasises how much there is still to find out; a chapter on otters in captivity throws added light on behaviour, and enables the author to draw usefully on his own considerable experience of keeping otters. Most of the book, however, is devoted to a systematic account, with distribution map, of the eighteen recognised species, including the intriguing giant otter of Brazil which may reach a length of eight feet, and an excellent section on the sea otter. The general production and the photographic illustrations are first class. 